\title{
Advanced glycation end products in human optic nerve head
}

Shiro Amano, Yuichi Kaji, Tetsuro Oshika, Teruaki Oka, Rikuo Machinami, Ryoji Nagai, Seiko Horiuchi

Department of Ophthalmology, University of Tokyo School of Medicine, Tokyo, Japan

S Amano

Y Kaji

T Oshika

Department of Pathology, University of Tokyo School of Medicine, Tokyo, Japan T Oka

R Machinami

Department of Biochemistry, University of

Kumamoto School of Medicine, Kumamoto, Japan

R Nagai

S Horiuchi

Correspondence to: Shiro Amano, 7-3-1 Hongo, Bunkyo-ku, Tokyo,

113-8655 Japan

amanos-tky@umin.ac.jp

Accepted for publication 23 May 2000

Table 1 Clinical characteristics

\begin{tabular}{lllllll}
\hline Eye & Age & Sex & DM & DM type & $\begin{array}{l}\text { Duration of } \\
\text { DM }\end{array}$ & DM retinopathy \\
\hline 1 & 52 & F & - & - & - & - \\
2 & 62 & F & - & - & - & - \\
3 & 68 & M & - & - & - & - \\
4 & 69 & F & - & - & - & - \\
5 & 69 & F & - & - & - & - \\
6 & 75 & M & - & - & NA & NA \\
7 & 59 & M & + & NA & NA years & NA \\
8 & 60 & M & + & NIDDM & NA years & NA \\
9 & 64 & F & + & NIDDM & years & NA \\
10 & 65 & F & + & NIDDM & 23 years & Background \\
11 & 72 & M & + & NIDDM & years & Proliferative \\
12 & 74 & M & + & NIDDM & 28 years & NIDDM \\
13 & 78 & M & + & NIDDM & \\
\hline
\end{tabular}

$\mathrm{NA}=$ not available.

(Br F Ophthalmol 2001;85:52-55)

Age is a major risk factor for chronic open angle glaucoma (COAG). Virtually every study agrees that the prevalence of COAG increases with age of the population being considered. ${ }^{1-7}$ Diabetes is also reported to be a risk factor for COAG in several studies, ${ }^{8-12}$ although further information from population based studies is necessary to definitely prove the role of diabetes in the development of COAG. ${ }^{13}$ While direct mechanical damage to the optic nerve and/or microangiopathy in the optic nerve head is a possible contributing mechanism in the pathogenesis of glaucoma, ${ }^{14}$ the exact

\begin{abstract}
Aims-To localise advanced glycation end products (AGEs) in human optic nerve head.

Methods-Optic nerve samples from 13 elderly individuals (seven diabetics and six non-diabetics) were obtained at necropsy. Pyrraline, an advanced glycation end product, was immunohistochemically localised in the optic nerve heads.

Results-In the diabetic subjects, moderate to intense immunoreactivity for pyrraline was detected in sclera, pia mater, cribriform plates, connective tissues in the optic nerve, and around vessels in the optic nerve and pia mater. Immunoreactivity for pyrraline was also detected around retinal vessels. In the non-diabetic subjects, slight or no immunoreactivity for pyrraline was found in cribriform plates and around the optic nerve vessels. Conclusion-Accumulation of AGEs in cribriform plates and around vessels in the optic nerve may contribute to the development of optic neuropathy in diabetic patients.
\end{abstract} (Pierce, Rockford, IL, USA) hydrochloride and $2.5 \mathrm{mM}$ of N-hydroxysulphosuccinimide (Pierce, Rockford, IL, USA) at room temperature for 1 hour. The reaction was terminated by $20 \mathrm{mM}$ of 2 -mercaptoethanol and dialysed against phosphate buffered saline (PBS) for 24 hours. To raise the polyclonal antibody, $0.5 \mathrm{mg}$ of caproyl pyrraline conjugated $\mathrm{KLH}$ in $50 \%$ Freund's complete adjuvant was injected intradermally into a rabbit at 20 skin sites, followed by four booster injections with the same amount of hapten conjugated $\mathrm{KLH}$ in $50 \%$ Freund's incomplete adjuvant. The serum was taken 10 days after the final immunisation for 
Table 2 Pyrraline immunoreactivity

\begin{tabular}{|c|c|c|c|c|c|c|c|c|}
\hline \multirow[b]{2}{*}{ Eye } & \multirow[b]{2}{*}{ Retina } & \multirow{2}{*}{$\begin{array}{l}\text { Optic } \\
\text { nerve } \\
\text { axon }\end{array}$} & \multirow{2}{*}{$\begin{array}{l}\text { Cribriform } \\
\text { plates }\end{array}$} & \multirow[b]{2}{*}{ Sclera } & \multirow{2}{*}{$\begin{array}{l}\text { Pia } \\
\text { mater }\end{array}$} & \multicolumn{3}{|c|}{ Vessels in } \\
\hline & & & & & & retina & optic nerve & pia mater \\
\hline 1 & - & - & + & - & - & - & - & - \\
\hline 2 & - & - & - & - & - & - & - & - \\
\hline 3 & - & - & + & - & + & - & + & + \\
\hline 4 & - & - & + & - & + & - & + & + \\
\hline 5 & - & - & - & - & - & - & - & - \\
\hline 6 & - & - & + & - & - & - & - & ++ \\
\hline 7 & - & - & ++ & ++ & ++ & ++ & ++ & ++ \\
\hline 8 & - & - & ++ & ++ & ++ & ++ & ++ & ++ \\
\hline 9 & + & - & +++ & ++ & +++ & ++ & ++ & +++ \\
\hline 10 & + & - & ++ & ++ & ++ & ++ & ++ & ++ \\
\hline 11 & - & - & ++ & ++ & ++ & ++ & ++ & +++ \\
\hline 12 & + & - & +++ & ++ & +++ & ++ & ++ & +++ \\
\hline 13 & + & - & +++ & +++ & +++ & ++ & ++ & +++ \\
\hline
\end{tabular}

-=negative; +=weak immunoreactivity; ++=moderate immunoreactivity; +++=intense immunoreactivity.

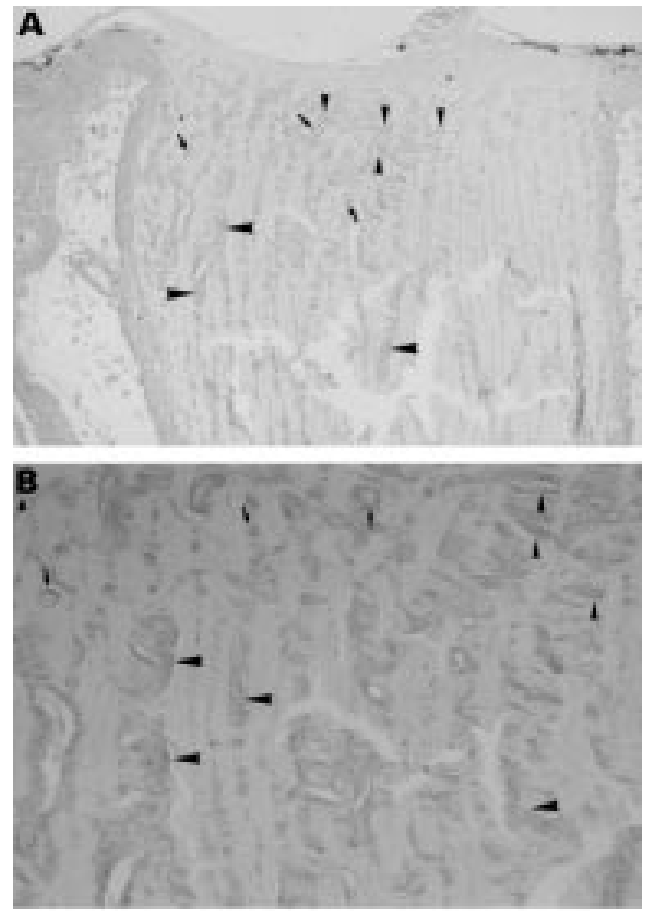

further affinity purification. The antiserum against hapten conjugated $\mathrm{KLH}$ was passed over $5 \mathrm{ml}$ of protein $\mathrm{G}$ immobilised sepharose gel (Amersham Pharmacia Biotech, Uppsala, Sweden). The column was extensively washed with PBS and eluted with $0.1 \mathrm{M}$ citric acid buffer ( $\mathrm{pH}$ 3.0). The pooled antibody fraction was neutralised, concentrated, and dialysed against PBS and used as affinity purified polyclonal antibody in the present study.

\section{IMMUNOHISTOCHEMISTRY}

Immunohistochemical staining was performed by the streptavidin-biotin-complex method. After fixation with $4 \%$ paraformaldehyde, optic nerve samples were embedded in paraffin. At least, 10 longitudinal sections $4 \mu \mathrm{m}$ thick were obtained in each optic nerve sample. The sections were preincubated in $1.0 \%$ hydrogen peroxide solution in PBS for 20 minutes at room temperature to inhibit the endogenous peroxidase activity. After washing with PBS three times for 10 minutes at $4^{\circ} \mathrm{C}$, the sections were incubated with $10 \%$ normal goat serum (Histofine, Nichirei, Tokyo) for 2 hours at room temperature to inhibit nonspecific binding. The sections were then exposed to primary antibody (rabbit polyclonal antibody for pyrraline) diluted to $1.0 \mathrm{mg} / \mathrm{ml}$ with PBS containing $1 \%$ bovine serum albumin and $0.04 \%$ sodium azide for 24 hours at $4^{\circ} \mathrm{C}$. After washing with PBS three times for 20 minutes at room temperature, secondary antibody (goat biotinylated anti-rabbit IgG: Histofine) was added for 2 hours at room temperature. The sections were then incubated with peroxidase conjugated streptavidin for 2 hours at room temperature. To visualise the immunoreactions, sections were incubated with diaminobenzidine (DAB) in PBS. Finally, sections were counterstained with haematoxylin. For negative control, we replaced the primary antibody with normal rabbit serum IgG $(1.0 \mathrm{mg} / \mathrm{ml})$ diluted with PBS containing $1 \%$ bovine serum albumin and $0.04 \%$ sodium azide. Following these preparations, the sections were processed to immunostaining as described above. The intensity of immunoreactivity was graded by a masked observer qualitatively as negative, weak, moderate, or intense.

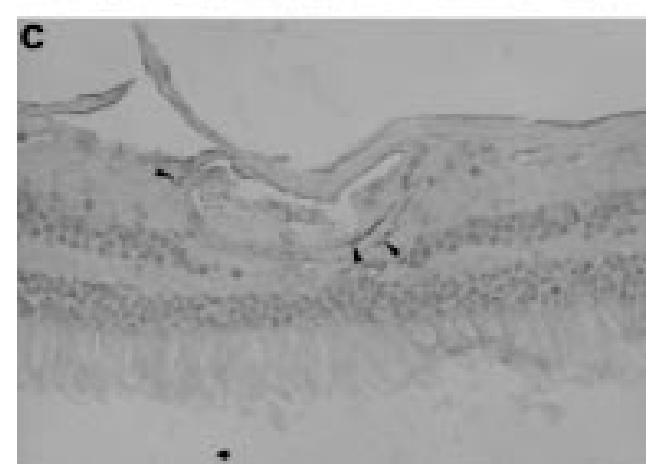

Figure 1 The results of immunohistochemistry in optic nerve head ( $A$ and $B$ ) and retina $(C)$ of a 72 year old diabetic man (case 11). Moderate to intense

immunoreactivity for pyrraline was detected in sclera, pia mater, cribriform plates (small arrowheads in $A$ and $B$ ), connective tissues in the optic nerve head (large arrowheads in $A$ and $B$ ), and around optic nerve vessels (small arrows in $A$ and $B$ ). There was no immunoreactivity in optic nerve axons. Immunoreactivity for pyrraline was also detected around retinal vessels (arrowheads in $C$ ). Original magnification, $\times 10(A), \times 25(B), \times 100(C)$.

\section{STATISTICAL ANALYSIS}

Since the sample number was small for statistical analysis, the intensity of immunoreactivity was reclassified into two groups: negative (negative or weak immunoreactivity) and positive (moderate or intense). Then, the immunoreactivity for pyrraline was compared between diabetics and non-diabetics using a two tailed Fisher's exact test, with $\mathrm{p}<0.05$ deemed significant.

\section{Results}

The results of immunohistochemistry are summarised in Table 2. In the diabetic subjects, moderate to intense immunoreactivity for pyrraline was detected in sclera, pia mater, cribriform plates, connective tissues in optic nerve, and around vessels in optic nerve and pia mater (Fig 1A and B). Immunoreactivity for pyrraline was also detected around retinal vessels (Fig 

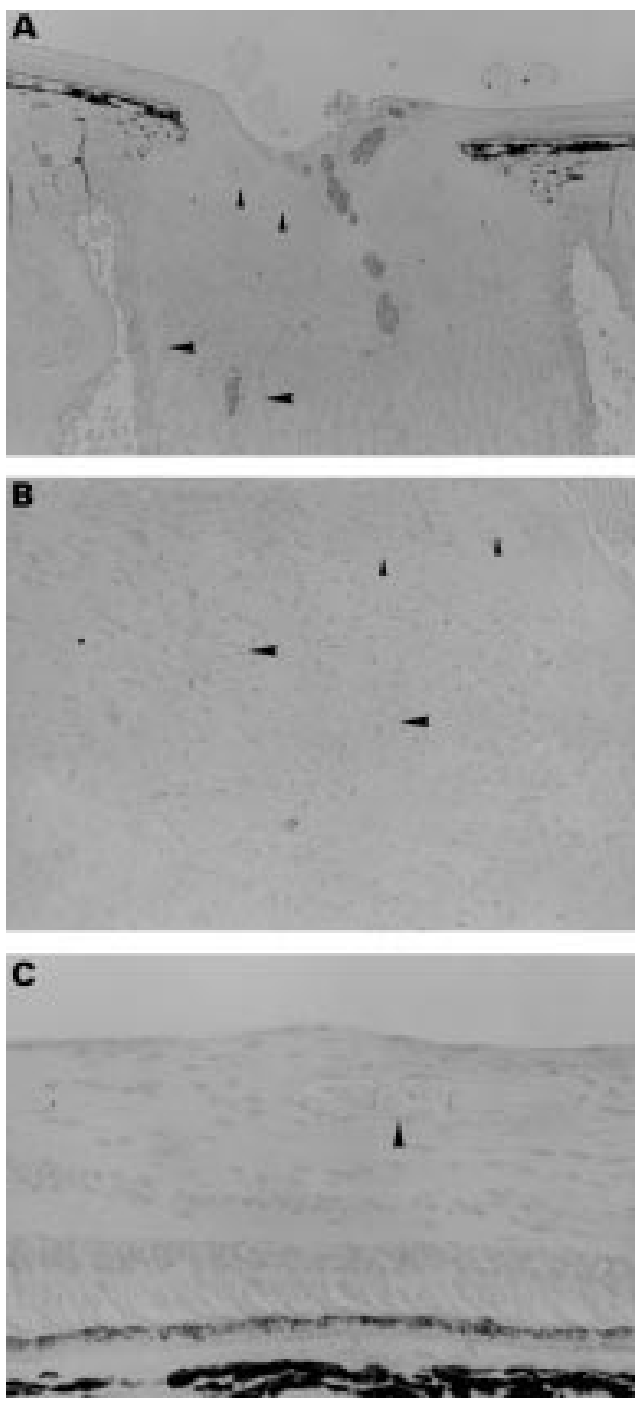

Figure 2 The results of immunohistochemistry in optic nerve head ( $A$ and $B)$ and retina $(C)$ of a 69 year old non-diabetic woman (case 5). There was no immunoreactivity in cribriform plates (small arrowheads in $A$ and $B)$, connective tissues in the optic nerve head (large arrowheads in $A$ and $B$ ), or around retinal vessels (arrowhead in C). Original magnification, $\times 10(A), \times 25$ (B), $\times 100(C)$.

1C). There was no immunoreactivity in optic nerve axons. In the negative controls in which normal rabbit serum IgG was used instead of primary polyclonal antibody to pyrraline, there was no immunoreactivity in optic nerve heads (data not shown).

In the non-diabetic subjects, slight or no immunoreactivity for pyrraline was found in cribriform plates and around optic nerve vessels (Fig 2A and B). There was no immunoreactivity in optic nerve axons (Fig $2 \mathrm{~B}$ ) and retinas (Fig 2C).

The differences in the intensity of pyrraline immunoreactivity between diabetics and nondiabetics were statistically significant in cribriform plates, sclera, pia mater, and vessels in each tissue $(\mathrm{p}<0.01)$.

\section{Discussion}

AGEs have been shown to accumulate in diabetic and ageing organs, ${ }^{15-17} 3031$ including ocular tissues (cornea, ${ }^{18}$ lens, ${ }^{19-21}$ vitreous, ${ }^{23}$ and retina $^{24}$ ). Accumulation of AGEs in ECM was shown to elicit several changes of ECM including decreased solubility, decreased susceptibility to enzymes, and changes in such properties as thermal stability, mechanical strength, and stiffness. $^{32-35}$ These changes in the physicochemical properties of ECM are believed to contribute, in part, to the development of age related changes and diabetic complications, including cardiovascular disease, retinopathy, nephropathy, indurated skin and joint stiffness. ${ }^{32}{ }^{36}$ Albon et $a l^{37}$ reported a linear age related increase of pentocidine, an advanced glycation end product, in lamina cribrosa. Accumulation of AGEs in ECM of optic nerve heads in the elderly may decrease elasticity of lamina cribrosa and compromise the ability of cribriform plates to bear the strain caused by elevated intraocular pressure. ${ }^{37}$ The results of the current study showed that accumulation of pyrraline in cribriform plates was accelerated in diabetics compared with non-diabetics, suggesting that the mechanical properties of the lamina cribrosa change more severely in diabetics than in non-diabetics. Such alterations in cribriform plates may contribute to more frequent development of glaucoma in diabetics.

Owing to the scarcity of samples, we could not examine the accumulation of pyrraline in younger subjects. We obtained one sample of a fetus of 34 weeks, in which immunoreactivity for pyrraline was completely absent in ECM and vessels in the optic nerve head (data not shown). A previous study ${ }^{37}$ demonstrated a linear age related increase of pentosidine in the lamina cribrosa in subjects ranging from 3 weeks to 92 years old. Thus, it is probable that pyrraline accumulates in lamina cribrosa with age.

Dramatic changes in ECM of lamina cribrosa in COAG have been reported including a decrease of collagen density and an appearance of masses of elastin. ${ }^{38}$ These changes in ECM may alter the mechanical properties of the tissue early in the disease. In the current series, optic nerve heads from eyes with glaucoma were not available. Examination of AGEs in glaucomatous subjects may further clarify the involvement of AGEs in the development of glaucoma.

AGEs have been shown to accumulate in myelin and tubulin of peripheral nerves. ${ }^{39-41}$ Non-enzymatic glycation of such neural proteins is thought to impair axonal transport, which may induce diabetic neuropathy. In the present study, immunoreactivity for pyrraline was not detected in neural component of optic nerves, suggesting that diabetic optic neuropathy is different from diabetic neuropathy in other peripheral nerves in that it is not induced by the accumulation of AGEs in the neural proteins.

In conclusion, advanced accumulation of AGEs in cribriform plates and around optic nerve vessels in diabetics may contribute to the development of optic neuropathy by compromising the ability of cribriform plates to bear 
the strain caused by elevated intraocular pressure and/or impairing the microcirculation.

The authors have no commercial or proprietary interest in the product or company described in this paper.

1 Bengtsson B. The prevalence of glaucoma. Br f Ophthalmol 1981;65:46-9.

2 Coffey M, Reidy A, Wormald R, et al. Prevalence of glaucoma in the west of Ireland. Br F Ophthalmol 1993;77: $17-21$.

3 Hollows FC, Graham PA. Intraocular pressure, glaucoma, and glaucoma suspects in a defined population. $\mathrm{Br} F \mathrm{Oph}$ thalmol 1966;50:570-86.

4 Klein BE, Klein R, Sponsel WE, et al. Prevalence of glaucoma: the Beaver Dam Eye Study. Ophthalmology 1992;99:1499-504

5 Tielsch JM, Sommer A, Katz J, et al. Racial variations in the prevalence of primary open-angle glaucoma: the Baltimore prevalence of primary open-angle glauco
Eye Survey, $¥ A M A 1991 ; 266: 369-74$

6 Armaly MF, Krueger DE, Maunder L, et al. Biostatistical analysis of the collaborative glaucoma study. Arch Ophthalmol 1980;98:2163-71.

7 Leske MC, Ederer F, Podgor M. Estimating incidence from age-specific prevalence in glaucoma. Am f Epidemiol 1981 113:606-13.

8 Becker B. Diabetes mellitus and primary open-angle glaucoma. Am f Ophthalmol 1971;71:1-16.

9 Klein BE, Klein R, Jensen SC. Open-angle glaucoma and older-onset diabetes: the Beaver Dam Eye Study. Ophthalmology 1994:101:1173-7.

10 Klein BE Klein R, Moss SE. Intraocular pressure in diabetic persons. Ophthalmology 1984;91:1356-60.

11 Wilson MR, Hertzmark E, Walker AM, et al. A case-control study of risk factors in open angle glaucoma. Arch Opthalmol 1987; 105:1066-71.

12 Dielmans I, de Jong PTVM, Stolk R, et al. Primary open angle glaucoma, intraocular pressure, and diabetes mellitus 5 .

13 Ellis JD, Morris AD, MacEwen CJ for the DARTS/MEMO collaboration. Should diabetic patients be screened fo glaucoma? Br f Ophthalmol 1999;83:369-72.

14 Wilson MR, Martone JF. Epidemiology of chronic openangle glaucoma. In: Ritch R, Shields MB, Krupin T, eds. The glaucoma. 2nd ed. St Louis: Mosby, 1996:753-68.

15 Makita Z, Radoff S, Rayfield EJ, et al. Advanced glycosylation end products in patients with diabetic nephropathy. N Engl f Med 1991;325:836-842.

16 Miyata S, Monnier V. Immunohistochemial detection of advanced glycosylation end products in diabetic tissues using monoclonal antibody to pyrraline. 7 Clin Invest 1992 89:1102-12.

17 Monnier VM, Sell DR, Nagaraj RH, et al. Maillard reaction-mediated molecular damage to extracellular matrix and other tissue proteins in diabetes, aging, and trix and other tissue proteins
uremia. Diabetes 1992;41:36-41.

18 Kaji Y, Usui T, Oshika T, et al. Advanced glycation end products in diabetic corneas. Invest Ophthalmol Vis Sci 2000;41:362-8.

19 Dunn JA, Patrick JS, Thorpe SR, et al. Oxidation of glycated proteins: age-dependent accumulation of $\mathrm{N}^{\varepsilon}$ (carboxymethyl) lysine in lens proteins. Biochemistry 1989; 28:9464-8.

20 Araki N, Ueno N, Chakrabarti B, et al. Immunochemical evidence for the presence of advanced glycation end products in human lens proteins and its positive correlation with aging. F Biol Chem 1992;267:10211-214.

21 Nagaraj RH, Sady C. The presence of a glucose-derived Mailard reaction product in the human lens. FEBS Lett 1996;382:234-8.
22 Nakayama $\mathrm{H}$, Mitsuhashi $\mathrm{T}$, Kuwajima s, et al. Immunochemical detection of advanced glycation end products in ens crystallins from streptozotocin-induced diabetic rat. Diabetes 1993;42:345-50

23 Stitt AW, Moore JE, Sharkey JA, et al. Advanced glycation end products in vitreous: Structural and functional implications for diabetic vitreopathy. Invest Ophthalmol Vis Sci 1998;39:2517-23.

24 Murata $\mathrm{T}$, Nagai $\mathrm{R}$, Ishibashi $\mathrm{T}$, et al. The relationship between accumulation of advanced glycation end products and expression of vascular endothelial growth factor in and expression of vascular endothelial growth fact

25 Hayase F, Nagaraj RH, Miyata S, et al. Aging of proteins: immunological detection of a glucose-derived pyrrole formed during maillard reaction in vivo. F Biol Chem 1989; 264:3758-64.

26 Sell DR, Monnier VM. Structure elucidation of a senescence cross-link from human extracelluar matrix. F Biol Chem 1989;264:21597-602.

27 Ahmed MU, Thorpe SR, Baynes JW. Identification of $\mathrm{N}^{\varepsilon}$-carboxymethyllysine as a degradation product of fructoselysine in glycated protein. F Biol Chem 1986;261: 4889-94.

28 Nakamura K, Hasegawa T, Fukunaga Y, et al. Crosslines A and $\mathrm{B}$ as candidates for the fluorophores in age- and diabetes-related cross-linked proteins, and their diacetates produced by Maillard reaction of $\alpha-\mathrm{N}$-acetyl-L-lysine with D-glucose. F Chem Soc Chem Commun 1992;14:992-4.

29 Njoroge FG, Sayre LM, Monnier VM. Detection of D-glucose-derived pyrrole compounds during Maillard reaction under physiological conditions. Carbohydr Res 1987; 167:211-20.

30 Mitsuhashi T, Nakayama H, Itoh T, et al. Immunochemical detection of advanced glycation end products in renal cortex from STZ-induced diabetic rat. Diabetes 1993;42:82632.

31 Makino H, Shikata K, Hironaka K, et al. Ultrastructure of nonenzymatically glycated mesangial matrix in diabetic nephropathy. Kidney International 1995;48:517-26.

32 Vlassara H, Bucala R, Striker L. Pathogenic effects of advanced glycation: Biochemical, biologic, and clinical implications for diabetes and aging. Lab Invest 1994;70: $138-51$

33 Andreassen TT, Seyer-Hansen K, Bailey AJ. Thermal stability, mechanical properties and reducible cross-links of rat tail tendon in experimental diabetes. Biochimica et Biophysica Acta 1981;677:313-7.

34 Winlove CP, Parker KH, Avery NC, et al. Interactions of elastin and aorta with sugars in vitro and their effects on biochemical and physical properties. Diabetologia 1996;39. 1131-9.

35 Bruel A, Oxlund H. Changes in biomechanical properties, composition of collagen and elastin, and advanced glycation endproducts of the rat aorta in relation to age. Atherosclerosis 1996;127:155-65.

36 Reiser KM. Nonenzymatic glycation of collagen in aging and diabetes. Proc Soc Exp Biol Med 1998;218:23-37.

37 Albon J, Karwatowski WSS, Avery N, et al. Changes in the collagenous matrix of the aging human lamina cribrosa. $\mathrm{Br}$ 7 Ophthalmol 1995;79:368-75.

38 Hernadez MR, Ye H. Glaucoma: changes in extracellular matrix in the optic nerve head. Ann Med 1993;25:309-15.

39 Vlassara H, Brownlee M, Cerami A, et al. Nonenzymatic glycosylation of peripheral nerve protein in diabetes melliglycosylation of peripheral nerve protein in dia
tus. Proc Natl Acad Sci USA 1981;78:5190-2.

40 Vlassara H, Brownlee M, Cerami A, et al. Excessive nonenzymatic glycosylation of peripheral and central nervous system myelin components in diabetic rats. Diabetes 1983; 32:670-4

41 Cullum NA, Mahon J, Stringer K, et al. Glycation of rat sciatic nerve tubulin in experimental diabetes mellitus. Diabetologia 1991;34:387-9. 